\title{
Fast quantitative PCR, locked nucleic acid probes and reduced volume reactions are effective tools for detecting Batrachochytrium dendrobatidis DNA
}

\author{
Gregory R. Ruthig ${ }^{1,2, *}$, Benjamin P. DeRidder ${ }^{1}$ \\ ${ }^{1}$ Department of Biology, Grinnell College, 1116 8th Avenue, Grinnell, Iowa 50112, USA \\ ${ }^{2}$ Present address: Department of Biology, North Central College, 30 North Brainard Street, Naperville, Illinois 60540, USA
}

\begin{abstract}
The fungal pathogen Batrachochytrium dendrobatidis threatens amphibian populations around the world. The ability to detect this pathogen on infected animals and in the environment is critical for understanding and controlling this pandemic. We tested several advances in quantitative PCR (qPCR) techniques to detect $B$. dendrobatidis DNA. We used a fast PCR thermocycler and enzymes that reduced the volume and the duration of the reaction. We also compared a conventional TaqMan minor groove binding (MGB) probe to an identical locked nucleic acid (LNA) counterpart. The fast qPCR reaction had a high degree of sensitivity to $B$. dendrobatidis DNA. The LNA probe was effective for detecting $B$. dendrobatidis DNA and produced results similar to those of the MGB probe. The modifications that we tested can improve the cost, time efficiency and specificity of quantitative PCR as a tool for detecting pathogen DNA.
\end{abstract}

KEY WORDS: Batrachochytrium dendrobatidis $\cdot$ Quantitative PCR $\cdot$ Locked nucleic acids $\cdot$ Minor groove binding probe $\cdot$ Amphibian disease

Resale or republication not permitted without written consent of the publisher

\section{INTRODUCTION}

The amphibian pathogen Batrachochytrium dendrobatidis has been implicated in the declines and extinctions of amphibian populations around the world (Berger et al. 1998, Garner et al. 2005, Lips et al. 2006). A critical component of the study of B. dendrobatidis is detecting the pathogen on infected amphibians (Hyatt et al. 2007) and in the environment (Kirshtein et al. 2007, Walker et al. 2007). Currently the US Fish and Wildlife Service is considering requiring that amphibians transported across state and national borders be tested for $B$. dendrobatidis infections under the US Lacey Act (Docket No. FWSR9-FHC-2009-0093), which would further increase the demand for testing.
Boyle et al. (2004) developed a quantitative realtime PCR (qPCR) method that is both specific to Batrachochytrium dendrobatidis (Boyle et al. 2004) and more sensitive than previously used histological detection methods (Kriger et al. 2006). Similar to the efforts for $B$. dendrobatidis, several research groups focusing on infectious disease have attempted to standardize the process of sample collection and analysis to provide consistency in data acquisition across laboratories and instrument platforms (Josefsen et al. 2009, Weidmann et al. 2010). In many of these studies, qPCR technology has replaced more conventional diagnostic approaches, and optimization of qPCR protocols has become the focus. Likewise, we tested several modifications of the Boyle et al. (2004) method that may improve 
cost, time efficiency, and specificity of the technique.

Recent advances in qPCR have broadened the capability and accessibility of this approach to pathogen detection. They include faster polymerase enzymes, lower cost instrumentation with increased temperature ramp speeds and lower reaction volume requirements, and development of different types of fluorescent probes for detection of target sequences.

First, we took advantage of new fast qPCR technology. The cost of fast quantitative machines is much lower than earlier instrument models, although the cost of fast reagents is slightly higher than their conventional counterparts. The greater detection sensitivity of the fast machines and the development of enzymes that can withstand faster temperature changes have reduced PCR reaction volumes and total cycle times from approximately $25 \mu \mathrm{l}$ and $2 \mathrm{~h}$, to $10 \mu \mathrm{l}$ and $30 \mathrm{~min}$, effectively lowering the actual cost per reaction. Yoder \& Fishel (2008) showed that, in many cases, fast qPCR technology is compatible with established detection protocols. In the present study, we attempted to reduce the reaction volume and cycle times of $25 \mu \mathrm{l}$ and $75 \mathrm{~s}$ used by Boyle et al. (2004) to $10 \mu \mathrm{l}$ and $21 \mathrm{~s}$.

Finally, we tested different qPCR probe chemistries to assess the relative effectiveness and benefit of each. We compared the efficacy of the TaqMan (Applied Biosystems) minor groove binder (MGB) probe used by Boyle et al. (2004) to more recently developed locked nucleic acid (LNA) probe chemistry (Vester \& Wengel 2004). Detection of genomic regions of interest requires sequence-specific primers that define the target area, while higher levels of specificity require the use of fluorescentlabeled probes that hybridize to a region between the primers and differentiate closely related sequences. The challenge of designing compatible primers and probes that satisfy reaction stringency requirements (i.e. have sufficiently high and matching melting temperatures $\left[T_{\mathrm{m}}\right]$ ) is exacerbated because candidate genomic regions for primer and probe design are often short and adenine/thyminerich. This problem has been solved by the use of TaqMan MGBs that are conjugated to the 3 '-end of TaqMan qPCR probes and stabilize hybridization of the probe DNA to its target sequence. The result is a shorter probe with a much higher $T_{\mathrm{m}}$. The use of an MGB probe proved key to the development of the standard Batrachochytrium dendrobatidis assay as reported by Boyle et al. (2004). TaqMan MGB probes have been the industry standard, but other probe types have since been developed that may be less expensive or provide greater flexibility for design and specificity.

LNA probes rely on modified nucleotide chemistry to enhance the thermal stability of the probe-target hybrid (Vester \& Wengel 2004). The conformational flexibility of LNA nucleotides is reduced by the presence of a methylene bridge connecting the 2 '-oxygen of the ribose to the $4^{\prime}$-carbon of the ribose ring, resulting in a locked 3 '-endo conformation (Letertre et al. 2003). By restricting intranucleotide movement, LNAs incorporated into probes increase the local organization of the phosphate backbone and enhance nucleotide affinity for hybridization with complementary non-LNA bases (Kaur et al. 2006).

In LNA probes, up to 6 of the DNA nucleotides are replaced with LNA nucleotides, increasing the $T_{\mathrm{m}}$ of the probe-target hybrid by 4 to $5^{\circ} \mathrm{C}$ per nucleotide (Vester \& Wengel 2004). This increase in thermal stability greatly enhances the specificity of probetarget hybridization. Several recent studies have compared the usefulness of MGB and LNA fluorescent probes for qPCR detection of bacterial and viral pathogens (Letertre et al. 2003, Rossmanith et al. 2006, Josefsen et al. 2009, Weidmann et al. 2010). The majority of these studies found LNA probes to be at least as reliable as MGB probes. We compared the MGB probe used to detect Batrachochytrium denrobatidis DNA by Boyle et al. (2004) with an identical LNA counterpart.

\section{MATERIALS AND METHODS}

\section{DNA extraction}

DNA was extracted from Batrachochytrium dendrobatidis that was originally isolated from a chorus frog Pseudacris maculata and maintained in a TGhL broth (16 g tryptone, $4 \mathrm{~g}$ gelatin hydrolysate, $2 \mathrm{~g}$ lactose, $10 \mathrm{~g}$ agar and $1000 \mathrm{ml}$ distilled $\mathrm{H}_{2} \mathrm{O}$ ) (Retallick \& Miera 2007). An aliquot of $50 \mu \mathrm{l}$ of TGhL broth containing $B$. dendrobatidis zoospores was added to $100 \mu \mathrm{l}$ of PrepMan Ultra (Applied Biosystems) and vortexed for $40 \mathrm{~s}$. This mixture was boiled for $10 \mathrm{~min}$ and allowed to cool for $2 \mathrm{~min}$. After cooling, the mixture was centrifuged for $2 \mathrm{~min}$ and $100 \mu \mathrm{l}$ of the supernatant was removed. A 1:10 dilution of the supernatant was used as an unknown in our qPCR tests.

Four DNA samples of Batrachochytrium dendrobatidis were obtained by O. Hyman, Arizona State University, from wild captured frogs. These samples were obtained by swabbing the frogs in the field (Hyatt et al. 2007). All 4 samples were swabbed from 
Pseudacris maculata adults in Arizona. The samples were found to be positive for $B$. dendrobatidis by using qPCR and following the protocol of Boyle et al. (2004) with a 384-well optical PCR plate on an ABI Prism 7900 Sequence Detection system (Applied Biosystems) at Arizona State University (O. Hyman pers. comm.).

A $30 \mu \mathrm{l}$ aliquot from each of the 4 DNA samples sent to us was cleaned by using the Qiaquick PCR Purification Kit (Qiagen, cat. no. 28104). After the cleaning steps, the DNA was eluted in $50 \mu \mathrm{l}$ of Buffer EB (Qiagen), according to the manufacturer's instructions. We tested these samples with our modified qPCR methods (see below) before and after cleaning.

\section{Real-time PCR assay}

Real-time qPCR assays were conducted on an Applied Biosystems StepOnePlus Real-Time PCR System. Each $10 \mu \mathrm{l}$ reaction contained $5 \mu \mathrm{l}$ TaqMan Fast Universal PCR Mastermix (2x) (Applied Biosystems), PCR primers (900 nM), an MGB or LNA probe $(250 \mathrm{nM})$ and $1 \mu \mathrm{l}$ DNA (Table 1). All reactions were prepared in triplicate. Each qPCR assay included controls with no DNA template and control reactions containing DNA from 100, 10, 1, and 0.1 Batrachochytrium dendrobatidis genome equivalents, according to Boyle et al. (2004). The default StepOnePlus amplification parameters $\left(20 \mathrm{~s}\right.$ at $95^{\circ} \mathrm{C}$ followed by 50 cycles of $1 \mathrm{~s}$ at $95^{\circ} \mathrm{C}$ and $20 \mathrm{~s}$ at $60^{\circ} \mathrm{C}$ ) were used, including analysis thresholds.

We tested the efficacy of 2 types of probes, the MGB probe (Applied Biosystems, sole source) used

Table 1. Per reaction recipe for fast quantitative PCR detection of Batrachochytrium dendrobatidis DNA. The primer and probe sequences were designed by Boyle et al. (2004). To reduce the chance of false negative results, DNA templates acquired from swabbed amphibians were cleaned by using the Qiaquick PCR Purification Kit. The default StepOnePlus amplification parameters $\left(20 \mathrm{~s}\right.$ at $95^{\circ} \mathrm{C}$ followed by 50 cycles of $1 \mathrm{~s}$ at $95^{\circ} \mathrm{C}$ and $20 \mathrm{~s}$ at $60^{\circ} \mathrm{C}$ ) were used and included the analysis thresholds

\begin{tabular}{|ll|}
\hline Reagent & Volume $(\mu \mathrm{l})$ \\
\hline TaqMan Fast Universal PCR Mastermix $(2 \times)$ & 5.0 \\
(Applied Biosystems) & \\
Forward primer: 18 $\mu$ M ITS 1-3 Chytr & 0.5 \\
Reverse primer: 18 $\mu$ M 5.8 S Chytr & 0.5 \\
Probe: $5 \mu$ M Chytr (LNA or MGB) & 0.5 \\
$\mathrm{H}_{2} \mathrm{O}$ & 2.5 \\
DNA template & 1.0 \\
\hline
\end{tabular}

by Boyle et al. (2004) and an LNA probe. The MGB probe sequence was identical to the one used by Boyle et al. (2004) (5'-6FAM-CGA GTC GAC AAA AT-MGBNFQ-3'). The LNA probe (Integrated DNA Technologies, sole US source) was identical in sequence and $T_{\mathrm{m}}$ to the Chytr MGB2 probe (Boyle et al. 2004), in which the LNA nucleotides (underlined) substituted for the middle 6 DNA nucleotides; the probe contained the same 5 '-fluorescent label but a different 3'quencher (5'-6FAM-CGA GTC GAC AAA AT-Iowa Black FQ -3'). The LNA probe was used with the same primers used for the MGB probe (Boyle et al. 2004). The forward primer (ITS1-3 Chytr) was 5'-CCT TGA TAT AAT ACA GTG TGC CAT ATG TC-3' and the reverse primer (5.8S Chytr) was 5'-AGC CAA GAG ATC CGT TGT CAA A-3'.

We compared the effect of qPCR run and qPCR probe (LNA or MGB) on the estimation of the amount of DNA in the sample collected from pure Batrachochytrium dendrobatidis culture with an ANOVA (Minitab 15) in which qPCR was run as a random factor in our model. We compared these factors in 3 qPCR runs. We also compared the estimation of the amount of DNA provided by the LNA or MGB probe for the 4 cleaned field-collected samples and from the sample collected from pure $B$. dendrobatidis by using a paired $t$-test (Minitab 15). Three replicates of each of these samples were tested with each probe, all within the same qPCR run.

\section{RESULTS}

The $10 \mu \mathrm{l}$ qPCR reactions successfully detected DNA in all of the standards and the pure culture of Batrachochytrium dendrobatidis DNA samples when we used the MGB and the LNA probes. qPCR reactions had mixed success at detecting the 0.1 zoospore standard. We included this 0.1 zoospore standard if it was detected and the $\mathrm{R}^{2}$ value for our standard curve was better than 0.99. All of the $\mathrm{R}^{2}$ values for our standard curves were above 0.99 when we removed the 0.1 zoospore standard from the regressions.

There were significant differences between the 3 qPCR runs in the estimates that they provided for the amount of DNA in the unknown sample (overall mean $=156.98 \pm 3.98[\mathrm{SE}]$ zoospore equivalents, $F=$ $237.52, \mathrm{p}=0.004)$. The MGB probe provided similar but significantly higher estimates for the unknown sample (159.17 \pm 5.91 zoospore equivalents) than did the LNA probe (154.17 \pm 6.30 zoospore equivalents).

None of the 4 field-collected DNA samples that had not been cleaned produced positive results when 
they were tested with the MGB and the LNA probes. All of these samples were positive when they were tested after their DNA was cleaned with the Qiaquick PCR Purification Kit.

When tested within the same qPCR run, the MGB and LNA probes produced nearly identical zoospore equivalent estimates for the cleaned DNA field samples and the DNA culture sample $(t=-0.49, \mathrm{p}=6.48$, $\mathrm{df}=4$ ). The mean estimate for the amount of DNA in the sample was $19.1 \pm 10.6$ for the MGB probe and was $20.3 \pm 10.1$ for the LNA.

\section{DISCUSSION}

We demonstrated that several modifications of the Boyle et al. (2004) qPCR technique are effective for detecting DNA of the amphibian pathogen Batrachochytrium dendrobatidis. By using a fast qPCR method, we reduced the amount of thermocycler time, and by using a $10 \mu \mathrm{l}$ reaction volume rather than $25 \mu \mathrm{l}$, we reduced reagent use by $60 \%$. An LNA probe was effective for detecting $B$. dendrobatidis DNA and produced different but very similar results when compared with a widely used MGB probe.

Both of the techniques positively identified the presence of Batrachochytrium dendrobatidis DNA, although the estimate for the amount of DNA in the unknown sample, given by the threshold cycle $\left(C_{\mathrm{t}}\right)$ values, differed between the 3 runs. This highlights the importance of using the same qPCR run to make direct comparisons between unknown samples. When the field-collected samples and the pure culture sample were compared within the same qPCR run, we found that the 2 probes produced nearly identical estimates for the number of zoospore equivalents for each of the samples. Most researchers studying $B$. dendrobatidis on DNA samples acquired from swabs of amphibian skin, however, use the technique to determine the presence or absence of the pathogen, rather than to determine an actual amount (G. R. Ruthig pers. obs.).

LNA probes offer several advantages to researchers as a tool to differentiate microbes from their close relatives. Because of the high thermal stability of LNA-DNA nucleotide pairs relative to the DNA-DNA base pairs found in TaqMan probetarget hybrids, LNA probes can distinguish between target sequences that differ by only one nucleotide. Compared with TaqMan probes, whose $T_{\mathrm{m}}$ decreases by only 1 to $3^{\circ} \mathrm{C}$ per nucleotide mismatch, a single nucleotide mismatch between an LNA probe and its target reduces $T_{\mathrm{m}}$ by an average of 4 to $5^{\circ} \mathrm{C}$, which is the mechanism for the higher specificity of LNA probes (Letertre et al. 2003, Vester \& Wengel 2004). For many microbes, such as members of the genus Aspergillus, closely related species or strains may have similar DNA sequences, but very different disease-causing capabilities (Henry et al. 2000). The high $T_{\mathrm{m}} \mathrm{S}$ of LNA probes, even in AT rich regions of the genome, can facilitate the design of specific probes for many different microbial systems (Letertre et al. 2003, Ugozzoli et al. 2004).

The modifications of the Boyle et al. (2004) qPCR methods that we tested will save time and money required to test for Batrachochytrium dendrobatidis DNA. Taking into account the current price of qPCR reaction reagents (mastermix, probe and primers) at the lowest available quantities, the cost to assay our samples in triplicate was US\$1.65, compared with $\$ 3.30$ per sample as described by Boyle et al. (2004). Considering that 27 samples are typically assayed in 96-well format (optical reaction plate plus adhesive cover) and allowing for the expense of one nontemplate control and 4 DNA standards, the adjusted average cost per experimental sample would be US\$2.52 for the fast method compared with $\$ 4.17$ for conventional assay conditions. It is important to note that the fast qPCR instrument is capable of supporting lower volume assays (10 $\mu$ l compared with $25 \mu \mathrm{l})$ owing to its greater sensitivity of detection and not because of the speed of the reaction or the physical nature of the reaction plates per se. The rapid cycle time of the fast qPCR reaction is further made possible by the nature of the polymerase enzymes in the fast qPCR mastermix. Consequently, the qPCR mastermix used in the study by Boyle et al. (2004) can also be used in $10 \mu \mathrm{l}$ volume reactions, as long as the assays are carried out on the fast qPCR instrument and in the longer duration format. Using the standard qPCR mastermix would reduce the cost per sample by US\$0.15 compared with using the fast qPCR mastermix employed in the present study. Thus, there is a small compromise between cost and time savings depending on the mastermix used. Finally, to circumvent potential problems associated with inhibition of qPCR, we found it necessary to clean up our samples (Qiagen), which added approximately US\$1.90 per sample. We did not make adjustments here for labor costs or machine use fees, considering that the reasonable cost of fast qPCR instrumentation (currently US\$40 000 for StepOnePlus) enables it to be acquired by individual research programs. It may be possible to realize additional cost savings by reducing the number of reaction replicates as suggested by Kriger et al. (2006). In summary, using fast 
qPCR and lower reaction volumes resulted in cost savings of approximately 25 to $50 \%$ over previously described methods. The LNA probes that we tested are similar to the MGB probes in their effectiveness and their cost but can be considered as an alternative to MGB probes. However, LNA probes may be a more useful option for researchers who are looking for qPCR probes with enhanced specificity in other systems.

Acknowledgements. E. W. Davidson provided the Batrachochytrium dendrobatidis pure culture. O. Hyman provided the $B$. dendrobatidis DNA acquired from field-captured frogs. Acquisition of the StepOnePlus instrument was made possible by a National Science Foundation grant to B.P.D. (Grant No. 0820756). The locked nucleic acid (LNA) probe was donated by Integrated DNA Technologies, $B$. dendrobatidis DNA standards were provided by D. Boyle at the Commonwealth Scientific and Industrial Research Organisation of Australia.

\section{LITERATURE CITED}

Berger L, Speare R, Daszak P, Green DE and others (1998) Chytridiomycosis causes amphibian mortality associated with population declines in the rain forests of Australia and Central America. Proc Natl Acad Sci USA 95: 9031-9036

Boyle DG, Boyle DB, Olsen V, Morgan JAT, Hyatt AD (2004) Rapid quantitative detection of chytridiomycosis (Batrachochytrium dendrobatidis) in amphibian samples using real-time Taqman PCR assay. Dis Aquat Org 60:141-148

Garner TWJ, Walker S, Bosch J, Hyatt AD, Cunningham AA, Fisher MC (2005) Chytrid fungus in Europe. Emerg Infect Dis 11:1639-1641

> Henry T, Iwin PC, Hinrichs SH (2000) Identification of Aspergillus species using internal transcribed spacer regions 1 and 2. J Clin Microbiol 38:1510-1515

Hyatt AD, Boyle DG, Olsen V, Boyle DB and others (2007) Diagnostic assays and sampling protocols for the detection of Batrachochytrium dendrobatidis. Dis Aquat Org 73:175-192

Josefsen MH, Löfström C, Sommer HM, Hoorfar J (2009)

Editorial responsibility: Cynthia Carey,

Boulder, Colorado, USA
Diagnostic PCR: comparative sensitivity of four probe chemistries. Mol Cell Probes 23:201-203

Kaur H, Arora A, Wengel J, Maiti S (2006) Thermodynamic, counterion, and hydration effects for the incorporation of locked nucleic acid nucleotides into DNA duplexes. Biochemistry 45:7347-7355

Kirshtein JD, Anderson CW, Wood JS, Longcore JE, Voytek MA (2007) Quantitative PCR detection of Batrachochytrium dendrobatidis DNA from sediments and water. Dis Aquat Org 77:11-15

Kriger KM, Hines HB, Hyatt AD, Boyle DG, Hero JM (2006) Techniques for detecting chytridiomycosis in wild frogs: comparing histology with real-time Taqman PCR. Dis Aquat Org 71:141-148

> Letertre C, Perelle S, Dilasser F, Arar K, Fach P (2003) Evaluation of the performance of LNA and MGB probes in 5'-nuclease PCR assays. Mol Cell Probes 17:307-311

> Lips KR, Brem F, Brenes R, Reeve JD and others (2006) Emerging infectious disease and the loss of biodiversity in a Neotropical amphibian community. Proc Natl Acad Sci USA 103:3165-3170

- Retallick RWR, Miera V (2007) Strain differences in the amphibian chytrid Batrachochytrium dendrobatidis and non-permanent, sub-lethal effects of infection. Dis Aquat Org 75:201-207

Rossmanith P, Krassnig M, Wagner M, Hein I (2006) Detection of Listeria monocytogenes in food using a combined enrichment/real-time PCR method targeting the prfA gene. Res Microbiol 157:763-771

Ugozzoli LA, Latorra D, Puckett R, Arar K, Hamby K (2004) Real-time genotyping with oligonucleotide probes containing locked nucleic acids. Anal Biochem 324:143-152

> Vester B, Wengel J (2004) LNA (locked nucleic acid): highaffinity targeting of complementary RNA and DNA. Biochemistry 43:13233-13241

Walker SF, Salas MB, Jenkins D, Garner TWJ and others (2007) Environmental detection of Batrachochytrium dendrobatidis in a temperate climate. Dis Aquat Org 77: 105-112

- Weidmann M, Faye O, Faye O, Kranaster R and others (2010) Improved LNA probe-based assay for the detection of African and South American yellow fever virus strains. J Clin Virol 48:187-192

Yoder KE, Fishel R (2008) Real-time quantitative PCR and fast QPCR have similar sensitivity and accuracy with HIV cDNA late reverse transcripts and 2-LTR circles. J Virol Methods 153:253-256

Submitted: July 29, 2010; Accepted: October 19, 2011

Proofs received from author(s): December 20, 2011 